\title{
Telomeric sequences of Asellus aquaticus (Crust. Isop.)
}

\author{
F. PELLICCIA*, E. V. VOLPI, V. LANZA, L. GADDINI, A. BALDINI \& \& A. ROCCHI \\ Dipartimento Genetica e Biologia Molecolare and Centro di Genetica Evoluzionistica del C.N.R., clo Dipartimento \\ Genetica e Biologia Molecolare, Università 'La Sapienza', 00185 Roma, Italy and $\ddagger$ Institute of Molecular Genetics, Baylor \\ College of Medicine, Houston, TX77030, U.S.A.
}

\begin{abstract}
The repeated sequence TTAGGG is present at all tested vertebrate telomeres including those of humans and at the telomeres of evolutionarily very distant organisms such as trypanosomes and slime moulds. We tested for the presence of this sequence in the genome of the crustacean isopod Asellus aquaticus. Fluorescence in situ hybridization and BAL31 nuclease digestion demonstrate that the (TTAGGG) ${ }_{n}$ sequence occurs at the extreme termini of the chromosomes and also at an interstitial site.
\end{abstract}

Keywords: Asellus, BAL31 nuclease, crustacean, in situ hybridization, isopod, telomere.

\section{Introduction}

In most eukaryotic organisms the ends of chromosomes consist of tandem repeats of short GC-rich sequences. The particular structural organization of these sequences, perhaps a four-stranded hairpin, stabilizes the telomeres. Their unique way of replication makes it possible to avoid the replicative shortening of the chromosomes in cells with unlimited proliferative capacity such as unicellular organisms, germline cells and immortalized cells (reviewed by Blackburn, 1991). The telomeric sequences of evolutionarily very distant organisms show remarkable similarity. In particular the same telomeric repeat TTAGGG is present at all tested vertebrate telomeres including those of humans and at the telomeres of trypanosomes and slime moulds (Van der Ploeg et al., 1984; Forney et al., 1987; Moyzis et al., 1988; Meyne et al., 1989).

In this work we tested for the presence of this sequence in the genome of the crustacean isopod Asellus aquaticus and its precise chromosome localization using fluorescence in situ hybridization and BAL31 nuclease digestion. The karyotype of $A$. aquaticus $(2 n=16)$ normally consists of eight homomorphic chromosome pairs. A heteromorphic chromosome pair has recently been identified in some of the males in a wild population (Fig. 1). The heterochromosome has two intercalary hetero-

\footnotetext{
*Correspondence.
}

chromatic areas containing ribosomal sequences and is inherited as a normal $\mathrm{Y}$ chromosome. The ribosomal genes are usually telomeric and associated with heterochromatin (Rocchi et al., 1984; Volpi et al., 1992).

\section{Materials and methods}

The study was carried out on a population of A. aquaticus collected from the Sarno river near Naples. Samples of DNA $(150 \mu \mathrm{g})$ were treated with BAL31 nuclease (Boehringer-Mannheim) to give a final concentration of $0.6 \mathrm{U} / \mu \mathrm{g}$ of genomic DNA and incubated at $30^{\circ} \mathrm{C}$. BAL 31 , tested on marker DNA fragments, digests at a rate of about $100 \mathrm{bp}$ per minute per molecular terminus. After 0, 40, 80 and $120 \mathrm{~min}$, EGTA was added to aliquots of DNA (final concentration 20 $\mathrm{mM}$ ). The aliquots were incubated at $65^{\circ} \mathrm{C}$ for $5 \mathrm{~min}$ to inhibit the BAL31 nuclease activity and then ethanol precipitated. Identical sets of DNA $(5 \mu \mathrm{g})$ from each time point were digested with one of the following restriction enzymes: AluI, DraI and HaeIII and then size fractionated on a 0.7 per cent agarose gel and blotted to nylon filters. The probes were: the insert of the plasmid pT4, containing more than 50 tandem repeats of hexamer TTAGGG, derived from Trypanosoma brucei telomeres, kindly provided by L. H. T. Van der Ploeg (Van der Ploeg et al., 1984), and the synthetic telomeric polymer (TTAGGG) ${ }_{7}$. The first probe was labelled by random priming technique using $\left(\alpha^{32} \mathrm{P}\right) \mathrm{dATP}$ (Amersham). Filters were prehybridized 

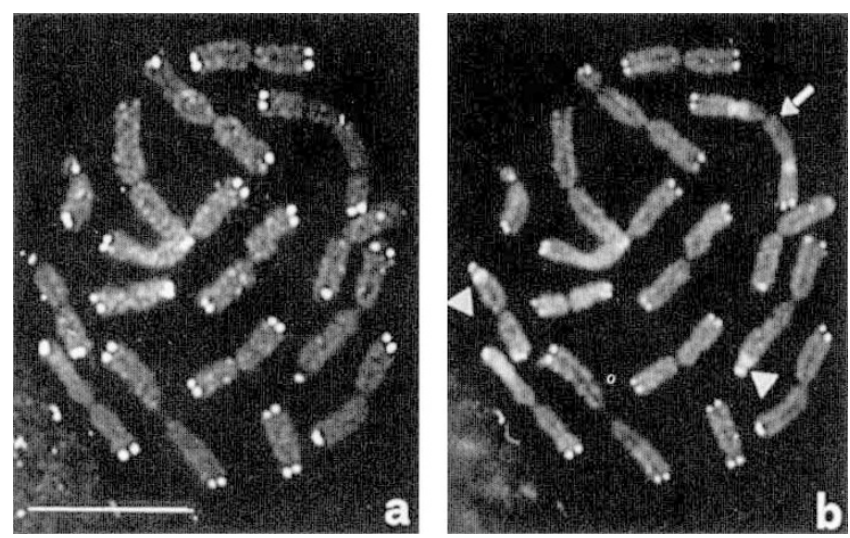

Fig. 1 Spermatogonial metaphase of $A$. aquaticus hybridized in situ with the biotin-labelled telomeric sequence repeat (TTAGGG) and detected by FITC-conjugated avidin (a). The same metaphase stained with chromomycin $\mathrm{A}_{3}$ to reveal the telomere constitutive heterochromatin (arrowheads) (b). Note the heterochromosome (arrow). Bar represents $10 \mu \mathrm{m}$.

at $68^{\circ} \mathrm{C}$ for $20 \mathrm{~h}$ in $5 \times$ Denhardt's, $6 \times \mathrm{SSC}, 0.5$ per cent SDS. Hybridization was carried out at the same temperature for $48 \mathrm{~h}$ in the same solution and followed by washes in $2 \times$ SSC 0.1 per cent SDS, $1 \times$ SSC 0.1 per cent SDS, $0.5 \times$ SSC 0.1 per cent SDS and $0.1 \times$ SSC 0.1 per cent $\mathrm{SDS}$ at $68^{\circ} \mathrm{C}$. The synthetic polymer was end-labelled using $\left({ }^{32} \mathrm{P}\right) \mathrm{dATP}$ (Amersham), prehybridized and hybridized at $55^{\circ} \mathrm{C}$ and washed with $6 \times \mathrm{SSC}$ 0.1 per cent SDS at $55^{\circ} \mathrm{C}$ and washed with $6 \times \mathrm{SSC}$ $0.1 \%$ SDS at $55^{\circ} \mathrm{C}$.

For in situ hybridization cytological preparations were obtained from squashes of testes $1.5 \mathrm{~h}$ after colchicine injection (concentration 0.5 per cent). The testes were fixed and squashed in 45 per cent acetic acid. Slides were ethanol dehydrated and stored desiccated at $-20^{\circ} \mathrm{C}$ for several days. The probe was the telomere repeat $(\text { TTAGGG) })_{\mathrm{n}}$ generated by PCR as described by Ijdo et al. (1991). This method produces a heterogeneous population of molecules consisting of repeat arrays of various length, up to $25 \mathrm{~kb}$. The probe was labelled by nick-translation with biotin 11-dUTP. Chromosome preparations were denatured in 70 per cent formamide $2 \times \mathrm{SSC}$ at $70^{\circ} \mathrm{C}$ and the hybridization was performed at $37^{\circ} \mathrm{C}$ in $4 \times \mathrm{SSC}, 20$ per cent formamide, 10 per cent $(\mathrm{w} / \mathrm{v})$ dextran sulphate and $0.3 \mu \mathrm{g} / \mu \mathrm{l}$ of sonicated salmon sperm DNA. Post-hybridization washes were at room temperature in $4 \times$ SSC, 20 per cent formamide (three times) followed by three washes in $4 \times \mathrm{SSC}, 0.1$ per cent Tween at $42^{\circ} \mathrm{C}$. Experiments using higher stringency post-hybridization washes were performed by increasing the percentage of formamide and reducing the salt concentration in the first three washes (50 per cent formamide, $2 \times \mathrm{SSC})$ and then washing three times in $2 \times \mathrm{SSC}$ at $42^{\circ} \mathrm{C}$. Biotin-labelled probe was detected using FITO-conjugated avidin. Chromosome preparations were simultaneously stained with DAPI. The hybridized specimens, after observation, were washed and then stained with chromomycin $\mathrm{A}_{3}$, to reveal the heterochromatic areas of the heterochromosome. Digital images were obtained using a computer controlled Zeiss Axioskop epifluorescence microscope equipped with a CCD camera. FITC and DAPI fluorescence, detected using specific filter combinations, were recorded separately as greyscale images and then pseudocoloured and merged using the software Genjoin (Yale University) or Pixel Paint Professional (Supermac).

\section{Results and discussion}

In situ hybridization with the telomeric synthetic probe (TTAGGG) ${ }_{n}$, resulted in labelling of all chromosomes of $A$. aquaticus at their ends only. No hybridization signals were observed at interstitial chromosome sites (Fig. 1a).

To verify that clusters of the (TTAGGG) $)_{n}$ sequence occur at the extreme termini of the chromosomes, we digested high molecular weight DNA of $A$. aquaticus with BAL31 nuclease for increasing amounts of time. This DNA was then cut using various restriction enzymes (AluI, DraI or HaeIII). The effect of BAL31 is to shorten the DNA molecules from their ends whereas it does not affect the internal sequences.

The results were similar with the three restriction enzymes used. The TTAGGG-rich probes detected two types of fragments. The first type consisted of heterogeneous DNA fragments, the larger part of which formed a high molecular weight smear between 22 and $13 \mathrm{~kb}$. These fragments were BAL31-sensitive, indicating that the TTAGGG tandem repeats are directly at the ends of A. aquaticus chromosomes as suggested by in situ hybridization (Fig. 2).

The dispersion of these fragments over several kilobases may be indicative of heterogeneous telomeric ends within different chromosomes and different tissues of this organism.

After 40 min of BAL 31 digestion we observed a reduction of the hybridization signal by about $4 \mathrm{kbp}$ and a considerable general decrease of labelling. The signal disappeared almost completely after $80 \mathrm{~min}$ of BAL31 digestion (Fig. 2).

The kinetics of BAL31 digestion allows us to estimate that the telomere repeats comprise not much more than $4 \mathrm{kbp}$ at the majority of chromosome ends. As most fragments containing the telomere repeats are very long, lacking AluI, DraI or HaeIII restriction sites 


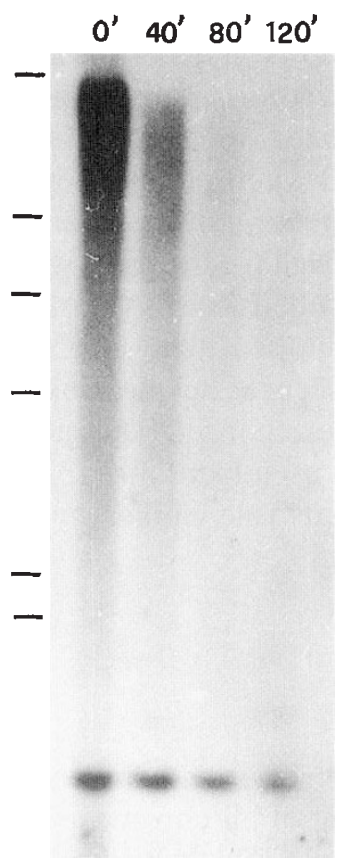

Fig. 2 Southern blot hybridization of genomic DNA of $A$. aquaticus digested with BAL31 nuclease for the times indicated in the figure and subsequently restricted with $A l u \mathrm{I}$. The probe was the insert of the plasmid pT4 containing more than 50 tandem repeats of examer TTAGGG. Lambda HindIII fragments were used as size markers $(23.3,9.4,6.6$, $4.3,2.3$ and $2.0 \mathrm{~kb}$ ).

for 13-22 kbp, we may advance the hypothesis that stretches of tandemly repeated subtelomeric sequences are present on chromosomes of A. aquaticus. Constitutive heterochromatic areas are well shown by chromomycin $\mathrm{A}_{3}$ fluorescence at some telomeric regions (Fig. $1 \mathrm{~b}$ ) but small quantities of heterochromatic sequences are probably present at all telomeres (Rocchi et al., 1980).

The second class of fragments detected by the TTAGGG-rich probes forms a discrete BAL31-insensitive band that does not therefore contain chromosome ends. These fragments are of about $1.3 \mathrm{kbp}$ with the AluI enzyme (Fig. 2) and of about 1.7 and $2.3 \mathrm{kbp}$, respectively, with HaeIII and DraI (not shown).

The number of repeats of the telomere-specific DNA sequence localized in non-telomeric regions could be so small that they might escape detection by in situ hybridization; this technique did not reveal any signals at interstitial chromosome sites (Fig. 1a).

The stringent conditions used for in situ and blot hybridization of probes containing the telomere sequence (TTAGGG) $)_{n}$ to chromosomes and DNA of A. aquaticus, can be taken as evidence that it is precisely this sequence that is present at the ends of chromosomes of this crustacean.
As mentioned above, the same sequence is the functional telomere of humans and of all tested vertebrate species (Meyne et al., 1989) and it is also present at the telomeres of trypanosoma (Van der Ploeg et al., 1984) and slime moulds (Forney et al., 1987).

Given the evolutionary distance that exists between these organisms, we probably have to accumulate results from a wider range of species before we can advance any consideration about conservation of telomeric repeats.

\section{Acknowledgements}

This work was supported by a grant from the Ministero della Università e della Ricerca Scientifica e Tecnologica (MURST), Italia and Consiglio Nazionale delle Ricerche (C.N.R.), Italia. We thank the Cenci Bolognetti Foundation for supplying the ${ }^{32}$ P-labelled nucleotides and T. Rand and D. C. Ward (Yale University School of Medicine) for the computer programs Genjoin and CCD image capture.

\section{References}

BLACKBURN, E. H. 1991. Structure and function of telomeres. Nature, 350, 569-573.

FORNEY, J., HENDERSON, E. R. AND BLACKBURN, E. H. 1987. Identification of the telomeric sequence of the acellular slime molds Didimium iridis and Physarum polycephalum. Nucleic Acids Res., 15, 9143-9152.

IJDO, J. W., WELlS. R. A., BALDINI, A. AND REEDERS, S. T. 1991. Improved telomere detection using a telomere repeat probe (TTAGGG) generated by PCR. Nucleic Acids Res., 19, 4780 .

MEYNE, J., RATLIFF, L. R. AND MOYZIS, R. K. 1989. Conservation of the human telomere sequence (TTAGGG) $)_{n}$ among vertebrates. Proc. Natl. Acad. Sci. USA, 86, 7049-7053.

MOYZIS, R. K., BUCKINGHAM, J. M., SCOTT CRAM, L., DANI, M., DEAVEN, L. L., JONES, M. D., MEYNE, J., RATLIFF, L. R. AND WU, J.-R. 1988. A highly conserved repetitive DNA sequence, (TTAGGG) is present at the telomeres of human chromosomes. Proc. Natl. Acad. Sci. USA, 85, 6622-6626.

ROCCHI, A., PRANTERA, G. AND DI CASTRO, M. 1980. A study of the heterochromatin of Asellus aquaticus (Crust. Isop.) Caryologia, 33, 401-409.

ROCCHI, A., PRANTERA, G., LANZA, v. AND DI CASTRO, M. 1984. Incipient sex chromosome differentiation in an isopod crustacean species, Asellus aquaticus. Chromosoma, 89, 193-196.

VAN DER PLOEG, L. H. T., LIN, A. Y. C. AND BORST, P. 1984. Structure of the growing telomeres of Trypanosomes. Cell, 36, 459-468.

VOLPI, E. V., PELLICCIA, F., LANZA, V., DI CASTRO, M. AND ROCCHI, A. 1992. Morphological differentiation of a sex chromosome and ribosomal genes in Asellus aquaticus (Crust. Isop.). Heredity, 69, 478-482. 